\title{
Clinical features and management of biliary ascariasis in a non-endemic area
}

\author{
S P Misra, Manisha Dwivedi
}

\begin{abstract}
Summary
Biliary ascariasis is common in certain geographical areas of the world. In India, it is common in the Kashmir valley and only stray cases have been reported from other parts of the country. Between January 1995 and May 1997, 14 patients with biliary ascariasis were seen at our centre, which is more than $1000 \mathrm{~km}$ from the Kashmir valley. The mean $( \pm$ SD) age of the patients was $31.7( \pm 6.1)$ years and all were females. None of them had been to a

must be aware of its clinical features and management.

In India, biliary ascariasis has been reported as being endemic in the Kashmir valley. ${ }^{5-8}$ Elsewhere in the country, only stray cases have been reported..$^{9-11}$ Of late we have encountered several patients with biliary ascariasis at our centre which is more than $1000 \mathrm{~km}$ from the Kashmir valley. ${ }^{12}$ In this report we present the clinical and ultrasonic features and management of such patients seen between January 1995 and May 1997.
\end{abstract} place known to be endemic for biliary ascariasis. Four patients presented with acute cholangitis, eight with acute abdominal pain and vomiting, and the remaining two were diagnosed incidentally during surgery for gallstone disease. Barring these two patients, ultrasound examination of the abdomen diagnosed the condition accurately. In 10 patients, a part of the worm was visible outside the papilla of Vater. The roundworm was caught in a Dormia basket and could be extracted in nine patients. In one patient the worm migrated inside the bile duct while it was being caught in a Dormia basket. In this and two other patients, in whom the worm had migrated completely inside the bile duct, worms were removed with the help of a Dormia basket after endoscopic sphincterotomy. There were no complications of endoscopic therapy. In the two patients in whom biliary ascariasis was detected during surgery, the worms were removed after choledocholithotomy. On a mean follow-up of $\mathbf{1 3 . 8}$ months, only one patient had a recurrence of biliary ascariasis. It is concluded that biliary ascariasis is not an uncommon disease and must be considered as a possibility in patients presenting with acute cholangitis and biliary pain even in a nonendemic area. Ultrasonography is an excellent diagnostic tool and endoscopic management is very effective and safe in the treatment of these patients.

Department of Gastroenterology, MLN Medical College, Allahabad 211001 , India

S P Misra

M Dwivedi

Submitted 20 May 1999 Accepted 19 August 1999
Keywords: ascariasis; bile duct; cholangitis

Biliary ascariasis is a common problem in certain areas of the world. ${ }^{1-4}$ Although it is not common in developed countries, with increasing air travel and immigration, clinicians in these countries may more often encounter patients with biliary ascariasis and, therefore,

\section{Materials and methods}

The clinical presentation, ultrasonographic findings, management and follow-up of patients diagnosed to have biliary ascariasis between January 1995 and May 1997 were recorded. In two patients biliary ascariasis was detected incidentally during surgery for cholelithiasis; these patients had undergone ultrasound examination 1 and 3 weeks before surgery, respectively. The other 12 patients underwent abdominal ultrasound examination just after being seen by the clinicians.

Endoscopic retrograde cholangiopancreatography was performed in all patients, except the two patients in whom the disease was detected during surgery. It was performed before removing the worm(s), in patients in whom the worm(s) had migrated fully inside the bile duct, and after removal of the worm(s) to confirm complete clearance of the bile ducts. In the two patients diagnosed during surgery, a T-tube cholangiogram was done to confirm ductal clearance.

Patients with acute cholangitis were managed with intravenous fluids, antibiotics and metronidazole. If a part of the roundworm was visible outside the papilla of Vater, it was caught in a Dormia basket and pulled out. If the worm or other worms had migrated in the bile duct, then a biliary endoprosthesis was placed in the bile duct and endoscopic sphincterotomy was performed after the patient had improved and the worms (living or dead) were removed.

In patients presenting with biliary pain and vomiting, if a part of the worm was visible outside, it was caught in a Dormia basket and extracted. If the worm had migrated fully inside the bile duct, then endoscopic sphincterotomy was performed and the worm(s) removed. 
All patients were given $400 \mathrm{mg}$ of albendazole po for three consecutive days and thereafter $400 \mathrm{mg}$ of albendazole every month po.

\section{Results}

The mean $( \pm$ SD) age of these patients was $31.7( \pm 6.1)$ years. All the patients were females. None of the patients had been to an area known to be endemic for biliary ascariasis. Four patients presented with acute cholangitis, eight with acute abdominal pain and vomiting, and the remaining two patients were diagnosed incidentally during surgery for gallstone disease. One patient gave a history of vomiting out a roundworm. None of the patients had undergone abdominal surgery or endoscopic sphincterotomy in the past.

Ultrasound examination did not reveal the presence of biliary ascariasis in the two patients in whom it was found incidentally during surgery for cholelithiasis. During the operation the surgeon felt cord-like objects in the dilated common bile duct and on choledocholithotomy two ascarides were removed from the common bile duct in one and three from the bile duct of the other patient. In the other 12 patients ultrasound examination of the abdomen showed the common bile duct to be dilated with a hyperechoic linear structure with a radiolucent central tube running across the bile duct (figure 1). In four patients the worm was seen to move inside the common bile duct.

Of the four patients presenting with acute cholangitis, the tail of the roundworm was visible outside the papilla of Vater in two patients. The tail was caught in a Dormia basket and the worms were extracted. In the third patient with acute cholangitis, a part of one worm was seen outside and was removed with a Dormia basket. Two other dead worms were present inside the common bile duct. A 7 Fr straight biliary endoprosthesis was placed in the bile duct and the patient managed conservatively. In the remaining patient the worm had migrated completely inside the bile duct. A 7 Fr straight biliary endoprosthesis was placed in the bile duct and the patient was managed conservatively. After both these patients improved, endoscopic sphincterotomy was per-

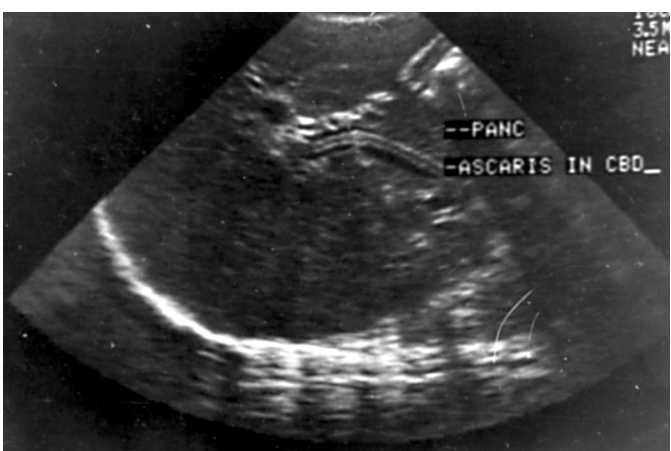

Figure 1 Abdominal ultrasound examination in a patient with biliary ascariasis. Note the presence of a linear hyperechoic structure with a central echo-free tube in the common bile duct. This ultrasonic appearance is typical of biliary ascariasis

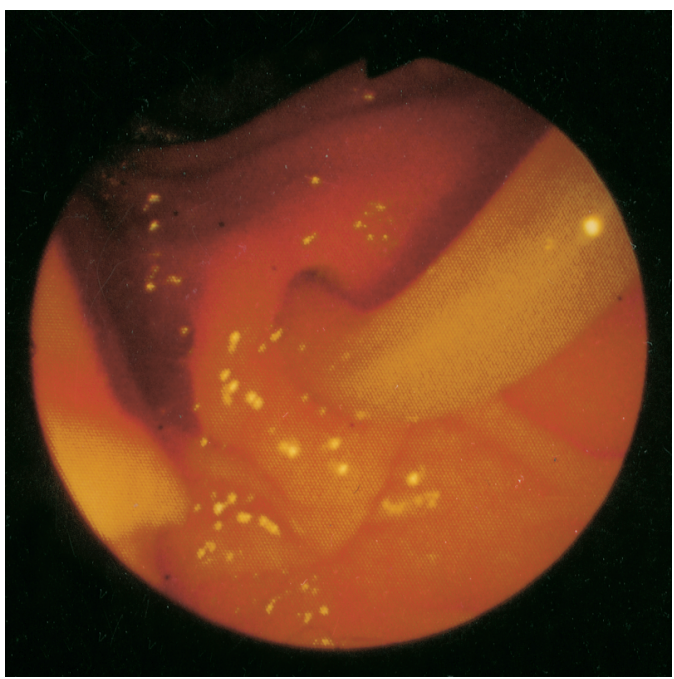

Figure 2 Endoscopic appearance in a patient with biliary ascariasis. The worm was caught in a Dormia basket and removed

formed and roundworms removed with the help of a Dormia basket.

Eight patients presented with abdominal pain and vomiting. A single worm was noted in each of these patients and a part of the worm was seen outside the papilla of Vater (figure 2). In seven patients the worms were caught in a Dormia basket and removed. In one patient, while the worm was being enclosed in the Dormia basket it migrated into the common bile duct. Endoscopic sphincterotomy was performed and the worm extracted with the help of a Dormia basket. All patients had immediate relief in symptoms after endoscopic management.

On a mean $( \pm$ SD) follow-up of $13.8( \pm 8)$ months, one patient, aged 27 years developed another episode of biliary pain and vomiting due to biliary ascariasis, two and a half months after the first episode. She had undergone endoscopic sphincterotomy for removal of a roundworm during the first episode. A part of the worm was seen outside the papilla of Vater. The tail of the worm was caught in a Dormia basket and the roundworm was extracted.

\section{Discussion}

Ascaris lumbricoides is a common parasite and over a billion people are estimated to be infested with it. ${ }^{13}$ There are several ways in which intestinal ascariasis can manifest. ${ }^{12} 1415$ However, the most dramatic and serious presentation is that of pancreatobiliary ascariasis. ${ }^{5-8} 12$ Although it is not a common problem in developed countries, with increasing air travel and immigration, it is increasingly likely that clinicians in these countries will encounter a patient with biliary ascariasis.

It is generally believed that, in India, biliary ascariasis is mostly confined to the Kashmir valley ${ }^{5-8}$ and only stray cases have been encountered outside Kashmir. ${ }^{9-11}$ However, the present study demonstrates that even in other parts of the country, biliary ascariasis may be a common problem and should be considered as 
a differential diagnosis in patients having acute abdominal pain and acute cholangitis. In the recent past we have reported endoscopyassisted emergency management of five cases of gastroduodenal and pancreatobiliary ascariasis. ${ }^{12}$ None of the patients in that report, nor those in the present series, had been to an area known to be endemic for biliary ascariasis.

Apart from the two patients in whom the diagnosis was made at laparotomy, the diagnosis was evident from the typical findings noted at ultrasonic examination of the abdomen. The ultrasonic appearance of biliary ascariasis has been described in detail. Features include the presence of long echogenic structures, linear or curved, single or multiple, with or without a central anechoic tube, mostly without acoustic shadowing. ${ }^{6}$ If the typical findings are not seen, choledocholithiasis may also be confused with biliary ascariasis, ${ }^{16}$ especially since acoustic shadowing may not be seen in about $10 \%$ of common bile duct stones. ${ }^{17-19}$

In two patients, ascarides were detected incidentally in the bile duct during surgery for gallstones, when the operating surgeon found the common bile duct to be dilated and felt cord-like structures within it. This led the surgeon to perform choledocholithotomy. Ultrasound examination of the abdomen, performed 1 and 3 weeks earlier had not detected ascarides in the bile ducts. While it may be possible that the ascarides were missed by the ultrasonologist, as there were multiple worms in both patients, it is more likely that the roundworms entered the bile ducts after the ultrasound examination was performed. Ultrasound examination has been noted to diagnose biliary ascariasis in $86 \%$ of patients having a single worm in the bile duct. However, all patients with two or more worms in the bile duct could be diagnosed accurately by ultrasonography. ${ }^{6}$

All patients in the present study were young or middle-aged females. Even in the Kashmir valley, where the disease is endemic, the disease is commoner in middle-aged females..$^{5-8}$ It is possible that in these young females, the hormone progesterone, leads to relaxation of the smooth muscles of the sphincter of Oddi, allowing the ascarides to gain easy entrance to the bile duct. Progesterone is a known inhibitor of smooth muscle contraction, ${ }^{20-24}$ and is also known to significantly increase gallbladder volume and decrease its emptying. ${ }^{25}$ A similar

1 Yang SCH, Laube PJ. Biliary ascariasis; report of 19 cases Ann Surg 1946;123:299-303.

2 Wright RM, Dorrough RL, Diltmore HB. Ascariasis of the biliary system. Arch Surg 1963;86:402-5.

3 Cremin BJ. Biliary parasites. Br f Radiol 1969;46:506-8.

4 Cremin BJ, Fischer RM. Biliary ascariasis in children. AfR 1976;126:352-7.

5 Khuroo MS, Zargar SA. Biliary ascariasis: a common cause of biliary and pancreatic disease in an endemic area. Gastroenterology 1985;88:418-23.

6 Khuroo MS, Zargar SA, Mahajan R, Bhat RL, Javid G. Sonographic appearances in biliary ascariasis. Gastroenterology 1987;93:267-72.

7 Khuroo MS, Mahajan R, Zargar SA, Javid G, Sapru S Prevalence of biliary tract disease in India: a sonographic study in adult population in India. Gut 1989;30:201-5.

8 Khuroo MS, Zargar SA, Mahajan R. Hepatobiliary and pancreatic ascariasis in India. Lancet 1990;335:1503-6.

\section{Learning points}

- biliary ascariasis is common, not only in the Kashmir valley of India, but also in other parts of the country and should be considered as a differential diagnosis in patients with biliary pain or acute cholangitis, even at centres where biliary ascariasis is not endemic

- ultrasound examination of the abdomen is an excellent tool in diagnosing the condition and endoscopic management yields excellent results

delay in the emptying of the gallbladder is seen in the normal menstrual cycle. ${ }^{26}$ However, the exact reason for the female preponderance is still not clear.

The management of biliary ascariasis is easy if a part of the worm is visible outside the papilla of Vater. The worm can then simply be caught and removed. However, if the worm has migrated fully inside the bile duct, then endoscopic sphincterotomy is required to pass retrieval devices inside the bile duct. Occasionally, however, the worm may migrate inside the bile duct in the process of being trapped in a retrieval device, as was noted in one of our patients.

In this study recurrence of biliary ascariasis was seen in only one patient. This was despite the patient receiving $400 \mathrm{mg}$ albendazole every month. The patient had undergone endoscopic sphincterotomy 10 weeks earlier to remove a roundworm from the bile duct. It is well known that re-infection commonly occurs in patients who have undergone endoscopic sphincterotomy in the past. ${ }^{6}$ In order to prevent such recurrences we have advocated endoscopic balloon dilation of the biliary sphincter instead of endoscopic sphincterotomy for removal of roundworms from the bile duct. ${ }^{27}$

Prior to the study period, we had not encountered any patient with biliary ascariasis at our centre. We were surprised to see the five cases of gastroduodenal and pancreatobiliary ascariasis ${ }^{12}$ and conjecture that the incidence of ascariasis is increasing. This is borne out by the fact that within such a short period of time we have encountered 14 patients with biliary ascariasis. It is known that poor sanitation, unplanned development with increasing urbanization and the use of human excreta as a fertilizer predispose to ascariasis. ${ }^{13}$

9 Aggarwal KK, Aggarwal SP, Aggarwal DC. Demonstration of a roundworm in the common bile duct. AfR 1964;91 869-70

10 Kalro RH, Ismail JH, Contractor QQ, Desai HG. Biliary ascariasis. Indian 7 Gastroenterol 1984;32:163-4.

11 Kamath PS, Joseph DC, Chandran R, Rao S, Sriprakash MK, D'Cruz AJ. Biliary ascariasis: ultrasonography, endoscopic retrograde cholangiography, and biliary drainage Gastroenterology 1986;91:730-2.

12 Misra SP, Dwivedi M. Endoscopy-assisted emergency management of gastroduodenal and pancreatobiliary ascariasis. Endoscopy 1996;28:629-32.

13 World Health Organization. WHO model prescribing information: drugs used in parasitic disease. Geneva: World Health Organization, 1990; pp 82-3.

14 Editorial. Ascariasis. Lancet 1989;i:997-8.

15 Bhasin DK, Chinna RS. Hematemesis in gastric ascariasis. Am f Gastroenterol 1989;84:12-3. 
16 Misra SP, Dwivedi M, Awasthi DN. Choledocholithiasis mimicking Ascaris lumbricoides: problem in ultrasound differential diagnosis. Trop Doc 1999;29:110-11.

17 Dewbury KC, Smith CL. The misdiagnosis of common bile duct stones with ultrasound. F Radiol 1983;56:625-30.

18 Einstein DM, Lapin SA, Rail PW. The insensitivity of sonography in the detection of choledocholithiasis. Am $\mathcal{F}$ Radiol 1984;142:725-8.

19 Kane RA. The biliary system. In: Kurtz AB, Goldberg BB, eds. Gastrointestinal ultrasonography. Clinics in diagnostic ultrasound. Edinburgh: Churchill Livingstone, 1988; pp 75-137.

20 Cohen S. The sluggish gallbladder of pregnancy. $N$ Engl f Med 1980;302:397-8.

$21 \mathrm{Abe} \mathrm{A}$. The hormonal control and effects of drugs and ions on the electrical and mechanical activity of the uterus. In Bulbring E, Brading A, Jones A, Tomito T, eds. Smooth mus cle. Baltimore: Williams and Wilkins, 1970; pp 396-417.
22 Somlyo AP, Somlyo AV. Vascular smooth muscle: pharmacology of normal and hypertensive vessels. Pharmacol Rev

23 Schulze K, Christensen J. Lower sphincter of the oppusum esophagus in pseudopregnancy. Gastroenterology 1977;73: 1082-5.

24 Fisher RS, Roberts GS, Grabowski CJ, Cohen S. Inhibition of lower esophageal sphincter circular muscle by female sex hormones. Am F Physiol 1978;234:E 243-7.

25 Everson GT, McKinley C, Lawson M, Johnson M, Kern F Jr. Gallbladder function in the human female: effect of the ovulatory cycle, pregnancy and contraceptive steroids. Gastroenterology 1982;82:711-9.

26 Nilsson S, Stattin S. Gallbladder emptying during the normal menstrual cycle. Acta Chir Scand 1967;133:648-52. 27 Misra SP, Dwivedi M. Removal of Ascaris lumbricoides from the bile duct using balloon sphincteroplasty. Endoscopy 1998;30:S6-7.

\section{Images in medicine}

\section{Needles should not be re-sheathed}

Re-sheathing needles is commonly practised despite universal condemnation. ${ }^{12}$ Even if this can be done without pricking oneself, another hidden danger is that of re-sheathing a large needle with a smaller sheath. It can be seen that the needle has penetrated the sheath and is therefore dangerous. Needles should not be re-sheathed under any circumstances.

A HUANG

Department of General Surgery

D DUTTA

Department of Anaesthetics Milton Keynes General Hospital, Standing Way, Eaglestone, Milton Keynes MK6 5LD, UK

Correspondence to Mr A Huang, 40 York Terrace East, London NW1 4PT, UK

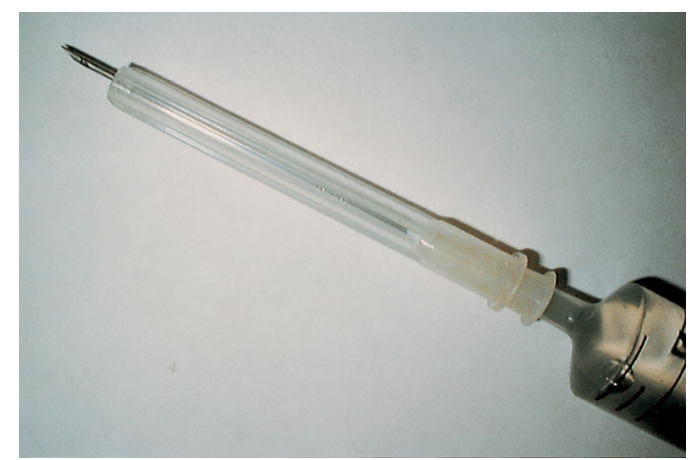

Submitted 12 August 1999 Accepted 19 August 1999

2 Guidance for clinical health care workers: protection against infection with HIV and hepatitis viruses. London: HMSO, 1990. 